\title{
灌浆温度和氮肥及其互作效应对稻米㫟藏蛋白组分的影响
}

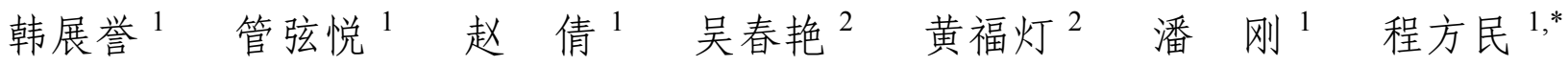

${ }^{1}$ 浙江大学农业与生物技术学院, 浙江杭州 $310058 ;^{2}$ 浙江省农业科学院, 浙江杭州 310021

摘 要: 灌浆结实期温度与氮肥施用量是影响稻米品质的两个重要生态因子, 尤其是与稻米蛋白含量及米饭食味关 系密切。本文以多个水稻主栽品种为材料, 通过灌浆结实期的人工控温试验、大田长期定位点的施氮处理试验和盆 栽条件下的温氮两因素复合处理试验, 探讨了水稻灌浆结实期温度对稻米冮藏蛋白含量与组分影响及其有别于氮肥 处理效应的差异规律, 并分析了温度与氮肥两个因素对稻米贮藏蛋白及其组分影响的交互作用特点。结果表明, 高温 胁迫和增施氮肥均引起水稻籽粒总蛋白及其谷蛋白组分含量 (\%)的显著增加, 但两者对稻米醇溶蛋白影响却存在明 显差别。其中, 高温处理引起醇溶蛋白含量显著下降, 提高稻米谷蛋白/醇溶蛋白比值, 而增施氮肥引起稻米谷蛋白 和醇溶蛋白含量明显增加, 但对谷蛋白/醇溶蛋白比值与贮藏蛋白各亚基的组成比例影响相对较小。在高温处理下, 谷蛋白的 $57 \mathrm{kD}$ 前体亚基组分含量有所提高, 而 $37 \mathrm{kD}$ 酸性亚基和 $22 \mathrm{kD}$ 碱性亚基随温度处理的差异变化却因品种 而异, 且高温处理对水稻籽粒蛋白绝对含量 $\left(\mathrm{mg} \mathrm{grain}^{-1}\right)$ 的影响程度也远没有其对蛋白相对含量 $(\%)$ 的影响明显。高氮 ×高温处理组合对稻米总蛋白与谷蛋白含量的影响程度显著大于单一高温或高氮处理, 但在高氮水平下由高温引起 稻米醇溶蛋白含量的下降幅度却小于其低氮对照, 有利于稻米醇溶蛋白含量在不同温度处理下的相对稳定。

关键词: 水稻; 灌浆温度; 氮肥; 贬藏蛋白; 稻米品质

\section{Individual and combined effects of air temperature at filling stage and nitrogen application on storage protein accumulation and its different components in rice grains}

HAN Zhan-Yu ${ }^{1}$, GUAN Xian-Yue ${ }^{1}$, ZHAO Qian ${ }^{1}$, WU Chun-Yan ${ }^{2}$, HUANG Fu-Deng ${ }^{2}$, PAN Gang ${ }^{1}$, and CHENG Fang-Min ${ }^{1, *}$

${ }^{1}$ College of Agriculture and Biotechnology, Zhejiang University, Hangzhou 310058, Zhejiang, China; ${ }^{2}$ Zhejiang Academy of Agricultural Sciences, Hangzhou 310021, Zhejiang, China

\begin{abstract}
Air temperature during grain-filling stage and application amount of nitrogen fertilizer are two of most important factors affecting rice grain quality, which largely related to grain protein content and cooking palatability. In this paper, the difference in grain protein content and its composition was investigated using different rice varieties, with different temperature treatments under artificial controlled condition and three nitrogen application levels in a long-term experiment field. Meanwhile, another experiment of two factors (temperature and nitrogen) in pot condition was conducted to clarity the interaction effects of temperature and nitrogen on grain protein content and its components. The higher temperature (HT) and heavier N application (HN) significantly enhanced the total protein content and glutelin accumulation in rice grain. However, HT differed obviously from HN in their impact on grain prolamin. HT significantly decreased grain prolamin concentration and markedly enhanced the ratio of glutelin to prolamin in rice grains, while $\mathrm{HN}$ increased in grain glutelin and prolamin contents had smaller effects on ratios of glutelin to prolamin and the proportion of subunit compositions in grain storage proteins. Furthermore, HT had a marked impact on the glutelin composition in rice grains, with the significant increase in $57 \mathrm{kD}$ pro-glutelin amount. However, the effect of HT
\end{abstract}

本研究由国家自然科学基金项目(31871566)和国家重点研发计划项目(2016YFD0300502, 2017YFD0300103)资助。

This study was supported by the National Natural Science Foundation of China (31871566) and the National Key Research and Development Program of China (2016YFD0300502, 2017YFD0300103).

*通信作者(Corresponding author): 程方民, E-mail: chengfm@zju.edu.cn

第一作者联系方式: E-mail: 21716125@zju.edu.cn

Received (收稿日期): 2019-11-28; Accepted (接受日期): 2020-03-24; Published online (网络出版日期): 2020-04-10.

URL: http://kns.cnki.net/kcms/detail/11.1809.S.20200410.1613.010.html 
on $37 \mathrm{kD} \alpha$-glutelin and $22 \mathrm{kD} \beta$-glutelin was greatly variable among different rice varieties. The varying extent of grain protein amount per grain $\left(\mathrm{mg}_{\text {grain }}{ }^{-1}\right)$ affected by HT was much smaller than that of grain protein content $(\%)$. The combined effect of HT and $\mathrm{HN}$ on the total storage protein and glutelin accumulation in rice grain was much greater than the individual effect of HT and HN. The dropping extent of grain prolamin content under HT appeared to be smaller for HN relative to LN, suggesting that appropriate $\mathrm{N}$ application was beneficial to keep the relatively stable content of grain prolamin composition under the fluctuating temperature for rice growth.

Keywords: rice (Oryza sativa L.); high temperature; nitrogen; storage protein; grain quality

稻米品质是品种基因型与环境生态因素共同作 用的结果, 灌浆结实期温度与氮肥施用量是影响稻 米品质的两个重要生态因子 ${ }^{[1-2]}$ 。现已基本明确, 灌 浆结实期高温会引起稻米整精米率下降、严白度增 加和稻米蒸煮食味品质变劣 ${ }^{[2-4]}$, 水稻生育后期氮素 营养不足或氮肥施用过量均不利于稻米品质改良 ${ }^{[5-9]}$ 。 其中, 氮素营养不足会引起水稻生育后期功能叶片 的提早衰老和光合同化物生产能力迅速下降 ${ }^{[10]}$, 导 致籽粒灌浆充实不良、稻米严白度增加、整精米率 下降, 但氮素穗肥施用过大, 则会引起稻米蛋白含量 偏高、米饭色泽和透明度变差、食味口感下降 ${ }^{[11-12]}$ 。

咜藏蛋白是稻米的第二大类化学组分, 它不仅 是评价稻米营养品质的一个重要指标, 而且与稻米 外观、蒸煮食味品质也存在密切联系 ${ }^{[13]}$ 。一般认为, 蛋白质含量过高会引起稻米食味品质变差 ${ }^{[1,7-9,11]}$, 但陈能等 ${ }^{[14]}$ 认为, 两者的负相关性并不显著。据 Champagne 等 $^{[5]}$ 和姚姝等 ${ }^{[12]}$ 报道, 尽管蛋白质含量 对食味有一定程度的影响, 但品种类型不同, 其影 响程度各异。稻米蛋白质对其蒸煮食味品质的负面 效应，只有在蛋白质含量超过一定的上限指标 $(6 \%$ $7 \%)$ 后才会体现 ${ }^{[14-15]}$ 。此外, 稻米蛋白含量对米饭色 泽和食味口感的影响, 也与其咜藏蛋白组分差异及 其亚基构成等因素有关。据 Hamaker 等 ${ }^{[16-17]}$ 报道, 稻 米蛋白质中的谷蛋白和球蛋白是由一些优良氨基酸 组成, 属营养丰富且不影响米饭食味的蛋白质, 只 有阻碍淀粉网眼状结构发展的醇溶蛋白才是导致米 饭食味降低的䛎藏蛋白组分。但 Lin 等 ${ }^{[18]}$ 认为, 稻 米谷蛋白对淀粉的糊化和膨胀具有抑制作用, 其含 量高低与稻米糊化温度、胶稠度等品质指标呈显著 负相关, 占稻米咜藏蛋白含量 $80 \%$ 左右的谷蛋白含量 增加会降低稻米蒸煮食味品质。近年来的水稻优质 栽培实践表明, 灌浆结实期高温和氮肥施用过量均 会引起稻米蛋白质含量增加和米饭食味下降 ${ }^{[6-12]}$, 但对于不同生态条件下稻米蛋白质含量与其蒸煮食 味品质间的相互关系, 尤其是灌浆结实期高温对稻 米聍藏蛋白组分的影响及其有别于氮肥效应的理化 生态特点, 迄今尚缺乏较明确认识。为此, 本研究以
多个水稻主栽品种为材料, 通过人工控温试验、大 田氮肥试验、温氮两因素互作试验, 比较分析水稻 䛎藏蛋白含量及其组分的差异变化, 旨在揭示灌浆 结实期高温与氮肥施用量对稻米䛎藏蛋白组分的影 响及其交互效应, 为稻米营养品质改良以及通过品 种选育和栽培调控等措施来协调稻米营养品质与蒸 煮食味品质间的关系提供理论依据。

\section{1 材料与方法}

\section{1 温度处理试验}

温度处理试验于 2017 年在浙江大学紫金港校 区农业试验站进行。供试水稻品种为浙恢 7954、黄 华占、秀水 134 、秀水 09 、9311 和角优 2640。其中, 浙恢 7954、黄华占、9311 为籼稻品种, 秀水 134 和 秀水 09 为粳稻品种, 角优 2640 是籼粳亚种间杂交 稻品种。5 月 20 日播种, 采用湿润育秋, 6 月 15 日 移栽, 各品种在田间随机排列, 每个品种在田间种 植 2 个小区, 每小区面积 $9 \mathrm{~m}^{2}$, 栽插密度为 $18 \mathrm{~cm} \times$ $20 \mathrm{~cm}$, 单本栽插, 待各品种分别在田间生长至孕穗 后期, 选取发育进程与长势基本一致的稻株 10 株, 带泥移入盆钵培育 7 10 d 至抽穗开花期, 选同日开 花且发育良好的单穗挂牌, 并在花后第 4 天将稻株 移入人工气候箱进行灌浆结实期的不同温度处理 (每个品种在每个气候箱中各放 3 4 盆), 直至水稻 成熟收获。

使用 2 台 CONVIRON 人工气候箱, 设常温(日 均温度 $23^{\circ} \mathrm{C}$ ) 和高温度(日均温度 $32^{\circ} \mathrm{C}$ ) 2 个处理, 由 程序自动控温, 模拟自然气候日变化, $24 \mathrm{~h}$ 连续运 转。每日 14:00 为最高温、5:00 为最低温, 期间温度 以 $1{ }^{\circ} \mathrm{C}$ 为间隔呈线性增加。其中, 常温处理的最高温 度和最低温度分别为 $26^{\circ} \mathrm{C}$ 和 $20^{\circ} \mathrm{C}$, 高温处理时的最 高温度和最低温度分别为 $36^{\circ} \mathrm{C}$ 和 $28^{\circ} \mathrm{C}, 2$ 台气候箱 中的其他气候因子均保持完全一致。其中, 光照时 间为 6:00-19:00, 光照强度为 $120 \sim 150 \mathrm{~J} \mathrm{~m}^{-2} \mathrm{~s}^{-1}$, 相 对湿度为 $75 \% \sim 80 \%$, 风速 $0.5 \mathrm{~m} \mathrm{~s}^{-1}$ 。

\section{2 氮素(肥)处理试验}

试验于 2018 年在浙江省农业科学院海宁试验 
基地进行。供试水稻品种为浙恢 7954、黄华占、秀 水 134 、秀水 09 。设不施氮肥(N0)、180 $\mathrm{kg} \mathrm{hm}^{-2}(\mathrm{MN})$ 和 $300 \mathrm{~kg} \mathrm{hm}^{-2}(\mathrm{HN}) 3$ 个氮处理水平, 氮肥为主区, 品种为裂区, 小区面积为 $6.0 \mathrm{~m} \times 4.0 \mathrm{~m}$, 设 3 次重复, 共 12 个小区。氮肥依据含氮率折合成尿素按基肥 : 分菜肥: 穗肥为 $4: 3: 3$ 施用, 并依此比例来确定 各处理不同生育时期的氮素施用量。试验地前茬为 油菜，土壤含有机质 $2.41 \%$ 、全氮 $0.15 \%$ 、碱解氮 $104.55 \mathrm{mg} \mathrm{kg}^{-1}$ 、全磷 $0.14 \%$ 、速效磷 $107.18 \mathrm{mg} \mathrm{kg}^{-1}$ 、 全钾 $1.38 \%$ 、速效钾 $110.26 \mathrm{mg} \mathrm{kg}^{-1}$ 。5 月 25 日播种, 6 月 20 日移栽, 栽插密度为 $20 \mathrm{~cm} \times 20 \mathrm{~cm}$, 每穴 2 苗, 移栽前施过磷酸钙(含 $\mathrm{P}_{2} \mathrm{O}_{5} \quad 13.5 \%$ ) $250 \mathrm{~kg} \mathrm{hm}^{-2}$ 和氯化钾(含 $\mathrm{K}_{2} \mathrm{O} 52 \%$ ) $200 \mathrm{~kg} \mathrm{hm}^{-2}$, 不同氮处理的 磷肥与钾肥施用量相等。大田常规水作栽培管理, 不同施氮处理间做埂隔开, 用塑料薄膜覆盖埂体, 保证各处理单独排灌，成熟后收获籽粒用于稻米品 质指标测定。

\section{3 温度与氮肥(素)两因素处理试验}

试验于 2018 年在浙江大学紫金港校区农业试 验站进行, 供水稻材料为浙恢 7954。5 月 15 日播种, 大田湿润育秧, 6 月 12 日移栽至盆钵, 盆钵直径 $25 \mathrm{~cm}$ 、高 $30 \mathrm{~cm}$, 内装过筛土约 $15 \mathrm{~kg}$ 。盆钵土壤 2017 年取自浙江省农业科学院海宁试验基地, 土壤 含有机质 $2.34 \%$ 、全氮 $0.13 \%$ 、速效氮 $96.35 \mathrm{mg} \mathrm{kg}^{-1}$ 、 全磷 $0.17 \%$ 、速效磷 $120.41 \mathrm{mg} \mathrm{kg}^{-1}$ 、全钾 $1.45 \%$ 、 速效钾 $110.26 \mathrm{mg} \mathrm{kg}^{-1}$ 。土壤经自然风干、充分浸泡 和充分混匀后, 分别装入不同盆钵(共 48 盆)。移栽 前每盆施 $2 \mathrm{~g}$ 尿素和 $0.5 \mathrm{~g} \mathrm{KH}_{2} \mathrm{PO}_{4}$ 做基肥, 移栽后 $7 \mathrm{~d}$ 每盆施 $0.5 \mathrm{~g}$ 尿素。在水稻生长至穗分化期(叶龄 余数为 $1.5 \sim 1.2$ 时)实施氮肥处理。其中, 低氮处理水 平 $(\mathrm{LN})$ 每盆施 $0.5 \mathrm{~g}$ 尿素, 高氮处理水平 $(\mathrm{HN})$ 每盆施 $2.0 \mathrm{~g}$ 尿素。每个氮处理水平 24 盆, 盆钵水稻放置于 大型智能温室 $\left(28^{\circ} \mathrm{C}\right.$ 白天 $/ 22^{\circ} \mathrm{C}$ 夜间 $)$ 生长, 温室内自 然光照, 每 $3 \mathrm{~d}$ 左右浇 1 次水, 及时防控病虫。待盆 钵水稻在大型智能温室生长发育至齐穗期, 选同日 开花且发育良好的单穗挂牌, 并将每个氮肥处理的 盆钵进一步分成 3 组 (每组 8 盆), 在挂牌标记稻穗开 花后的第 4 天, 分别将其盆钵移入 3 台 CONVIRON 人工气候箱实施不同温度处理, 待水稻在气候箱中 生长至成熟时，收获挂牌标记的稻穗。3 台 CONVIR $\mathrm{ON}$ 人工气候箱的温度处理设计为常温(日均温度 $23^{\circ} \mathrm{C}$, 日最高温度和最低温度分别为 $26^{\circ} \mathrm{C}$ 和 $20^{\circ} \mathrm{C}$ )、 高温 I (日均温度 $30^{\circ} \mathrm{C}$, 日最高温度和最低温度分别
为 $34^{\circ} \mathrm{C}$ 和 $26^{\circ} \mathrm{C}$ )、高温 II (日均温度 $34^{\circ} \mathrm{C}$, 日最高温 度和最低温度分别为 $38^{\circ} \mathrm{C}$ 和 $\left.30^{\circ} \mathrm{C}\right)$ 。温度日变化模 拟自然气候特征, 每日 14:00 为最高温、5:00 为最低 温, 期间温度以 $1^{\circ} \mathrm{C}$ 为间隔呈线性增加。3 台气候箱 中的其他气候因子均保持完全一致。其中，光照时 间为 6:00-19:00, 光照强度为 $120 \sim 150 \mathrm{~J} \mathrm{~m}^{-2} \mathrm{~s}^{-1}$, 相 对湿度为 $75 \% \sim 80 \%$, 凤速 $0.5 \mathrm{~m} \mathrm{~s}^{-1}$ 。

\section{4 籽粒总蛋白含量测定}

将成熟稻谷放在通风处 2 个月后, 去壳、磨粉 和过筛 $(0.25 \mathrm{~mm})$ 。参照 Luthe 等 ${ }^{[18]}$ 报道的方法略作 修改，采用凯氏定氮法测定籽粒粘米米粉总蛋白含 量。称取粘米粉 $200 \mathrm{mg}$, 倒入硝煮管, 加 $3 \mathrm{~g}$ 硫酸 钾：硫酸铜粉末(10：1, w/w), 再加 $8 \mathrm{~mL}$ 浓硫酸, 在硝煮仪(Tecator Digestor Auto, Foss)上 $360^{\circ} \mathrm{C}$ 煮 $150 \mathrm{~min}$, 将冷却后样品注入凯氏定氮仪, 蒸馏和滴 定过程自动运行, 记录下空白和样品消耗盐酸的体 积, 利用公式计算出总氮含量, 总蛋白含量等于总 氮含量 $\times 5.95$ 。

\subsection{4 种蛋白组分的提取与测定}

参照 Luthe 等 ${ }^{[19]}$ 和 Liu 等 ${ }^{[20]}$ 方法对 $0.5 \mathrm{~g}$ 䊁米米 粉中的 4 种蛋白组分进行分步提取。1)去离子水提 取清蛋白；2）2\%氯化钠提取球蛋白；3） $55 \%(\mathrm{v} / \mathrm{v})$ 正 丙醇提取醇溶蛋白；4） $0.24 \%$ 五水合硫酸铜、 $1.68 \%$ $\mathrm{KOH} 、 0.5 \%$ 酒石酸钾钠和 $50 \%(\mathrm{v} / \mathrm{v})$ 异丙醇混合溶液 提取谷蛋白。每次提取液用量为 $25 \mathrm{~mL}$, 室温下 $2 \mathrm{~h}$, 期间不断振荡, 其后 $4000 \times \mathrm{g}$ 离心 $10 \mathrm{~min}$, 重复提取 3 次。采用 Bradford 法 ${ }^{[19]}$ 测定清蛋白、球蛋白和醇 溶蛋白含量, 以牛血清蛋白为对照; 采用双缩腿法 测定谷蛋白含量 ${ }^{[20]}$, 仍以牛血清蛋白为对照, 并用 凯式法加以标定。

\section{6 蛋白亚基组成的 SDS-PAGE 分析}

参照 Yamagata 等 ${ }^{[21]}$ 方法进行稻米蛋白的 SDS-PAGE 分析。准确称取 $30 \mathrm{mg}$ 粘米粉于 $2 \mathrm{~mL}$ 离 心管中，加入 $1 \mathrm{~mL}$ 的 SDS-urea 提取液(4\%SDS、 $5 \%$

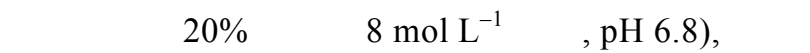
下过夜, 将混合液在 $20^{\circ} \mathrm{C} 15,000 \times g$ 离心 $20 \mathrm{~min}$, 上 清液用于点样。

取 $10 \mu \mathrm{L}$ 总蛋白提取液上样进行 SDS-PAGE 电 泳。采用分离胶浓度为 $12 \%$, 浓缩胶浓度均为 $5 \%$ 。 电极缓冲液为 $\mathrm{Tris}-\mathrm{HCl}$ 体系，含 $0.1 \% \mathrm{SDS}$ 。室温下 恒流 20 30 mA (起始 15 20 mA) 电泳 2 3 h 至溴酚 蓝泳动到胶板下缘停止, 取出凝胶板进行冲洗、固 定、染色、脱色等。最后将凝胶在 Bio-Rad GS-800 
扫描仪扫描，以 ImageJ 对染色凝胶中谷蛋白及其前 驱物的相对光密度进行估算。

\section{2 结果与分析}

\section{1 灌浆温度对水稻籽粒蛋白含量和组分的影响}

由表 1 可见, 高温处理会引起水稻籽粒总蛋白 含量(\%)的显著上升, 在 4 种蛋白组分中, 清蛋白、 球蛋白和谷蛋白组分含量 $(\%)$ 在高温处理下呈上升 趋势, 而多数品种的醇溶蛋白组分含量 $(\%)$ 在高温 处理下呈下降趋势。其中, 9311 在高温处理下的醇溶 蛋白含量 $(\%)$ 虽略有上升，但与其常温处理间的差 异末达统计显著水平。从单位籽粒蛋白绝对含量 $(\mathrm{mg}$ grain $^{-1}$ )来看, 浙恢 7954 和秀水 134 在高温处理下有 所上升 $\left(\mathrm{mg} \mathrm{grain}^{-1}\right)$, 但黄华占、秀水 $09 、 9311$ 和角 优 2640 在不同温度处理下的含量 $\left(\mathrm{mg} \mathrm{grain}^{-1}\right)$ 变化不 明显, 甚至略有降低。此外, 供试 6 个品种的谷蛋白 /醇溶蛋白比值在高温处理下均呈不同程度的上升 趋势(表 1)。上述现象说明, 高温处理虽然会引起水 稻籽粒总蛋白和谷蛋白组分的相对含量 $(\%)$ 有所提 高, 并显著提高水稻籽粒中的谷蛋白与醇溶蛋白比 值, 但单位籽粒中的谷蛋白积累量 $\left(\mathrm{mg} \operatorname{grain}^{-1}\right)$ 并不 一定会出现显著增加, 且醇溶蛋白占籽粒的百分相 对含量 $(\%)$ 和单位籽粒的醇溶蛋白绝对量 $\left(\mathrm{mg} \operatorname{grain}^{-1}\right)$
均有所下降。

利用 SDS-PAGE 对不同温度处理下籽粒咜藏蛋 白亚基差异的检测表明(图 1)，水稻籽粒諚藏蛋白主 要由 $57 \mathrm{kD} 、 37 \sim 39 \mathrm{kD} 、 22 \sim 23 \mathrm{kD}$ 和醇溶蛋白亚基 (prolamin)组成。其中, $57 \mathrm{kD} 、 37 \mathrm{kD}$ 和 $22 \mathrm{kD}$ 是 3 个谷蛋白亚基, 分别对应其 pro-glutelin、 $\alpha$-glutelin 和 $\beta$-glutelin。同一品种的不同温度处理间相比， $57 \mathrm{kD}$ 谷蛋白前体亚基(pro-glutelin)在高温处理下的 条带亮度相对较高, 而醇溶蛋白亚基在高温处理下 的条带亮度明显变暗。光密度扫描结果表明, 浙恢 7954 在高温处理下的 $57 \mathrm{kD}$ 谷蛋白前体亚基 (pro-glutelin)、37 kD 谷蛋白酸性亚基( $\alpha$-glutelin)和 $22 \mathrm{kD}$ 谷蛋白碱性亚基( $\beta$-glutelin)含量均高于其常温 对照, 而黄华占和秀水 134 在不同温度处理下的 $\alpha$-glutelin 亚基含量差异不明显。上述现象说明，高温 处理在引起水稻籽粒醇溶蛋白积累量降低的同时, 会 引起谷蛋白前体亚基(pro-glutelin)量的较明显增加。

\section{2 氮肥处理对水稻籽粒蛋白含量和组分的影响}

表 2 显示, 增施氮肥引起水稻籽粒总蛋白及其 4 种蛋白组分含量 $(\%)$ 的显著上升, 且高氮处理 $(\mathrm{HN})$ 下籽粒总蛋白、清蛋白、球蛋白、醇溶蛋白和谷蛋 白含量 $(\%)$ 通常高于中氮处理(MN)，但部分品种的 总蛋白、谷蛋白和醇溶蛋白在高氮处理 $(\mathrm{HN})$ 与中氮

表 1 不同温度处理下水稻籽粒蛋白含量及其组分差异

Table 1 Differences in total protein and its component contents in rice kernels between two temperature treatments

\begin{tabular}{|c|c|c|c|c|c|c|c|c|c|c|c|}
\hline \multirow[b]{2}{*}{$\begin{array}{c}\text { 品种 } \\
\text { Cultivar }\end{array}$} & \multirow[b]{2}{*}{$\begin{array}{c}\text { 处理 } \\
\text { Treatment }\end{array}$} & \multicolumn{5}{|c|}{ 相对含量 Relative content (\%) } & \multicolumn{5}{|c|}{ 绝对含量 Accumulation amount (mg grain ${ }^{-1}$ ) } \\
\hline & & $\begin{array}{c}\text { 清蛋白 } \\
\text { Albumin }\end{array}$ & $\begin{array}{l}\text { 球蛋白 } \\
\text { Globulin }\end{array}$ & $\begin{array}{c}\text { 醇溶蛋白 } \\
\text { Prolamin }\end{array}$ & $\begin{array}{l}\text { 谷蛋白 } \\
\text { Glutelin }\end{array}$ & $\begin{array}{c}\text { 总蛋白 } \\
\text { Total } \\
\text { protein } \\
\end{array}$ & $\begin{array}{c}\text { 清蛋白 } \\
\text { Albumin }\end{array}$ & $\begin{array}{l}\text { 球蛋白 } \\
\text { Globulin }\end{array}$ & $\begin{array}{c}\text { 醇溶蛋白 } \\
\text { Prolamin }\end{array}$ & $\begin{array}{c}\text { 谷蛋白 } \\
\text { Glutelin }\end{array}$ & $\begin{array}{l}\text { 谷/醇比 } \\
\text { Glu/Prol }\end{array}$ \\
\hline 浙恢 7954 & NT & $0.72 \mathrm{~b}$ & $0.80 \mathrm{~b}$ & $0.61 \mathrm{a}$ & $6.92 \mathrm{~b}$ & $9.17 \mathrm{~b}$ & $0.171 \mathrm{~b}$ & $0.190 \mathrm{a}$ & $0.145 \mathrm{a}$ & $1.644 \mathrm{~b}$ & $11.34 \mathrm{~b}$ \\
\hline Zhehui 7954 & HT & $1.06 \mathrm{a}$ & $0.95 \mathrm{a}$ & $0.57 \mathrm{~b}$ & $7.83 \mathrm{a}$ & $10.29 \mathrm{a}$ & $0.221 \mathrm{a}$ & $0.199 \mathrm{a}$ & $0.122 \mathrm{~b}$ & $1.678 \mathrm{a}$ & $13.74 \mathrm{a}$ \\
\hline 黄华占 & NT & $0.95 \mathrm{~b}$ & $0.93 \mathrm{~b}$ & $0.72 \mathrm{a}$ & $7.93 \mathrm{~b}$ & $10.46 \mathrm{~b}$ & $0.214 \mathrm{~b}$ & $0.209 \mathrm{~b}$ & $0.162 \mathrm{a}$ & $1.785 \mathrm{a}$ & $11.01 \mathrm{a}$ \\
\hline Huanghuazhan & HT & $1.15 \mathrm{a}$ & $1.02 \mathrm{a}$ & $0.65 \mathrm{~b}$ & $8.21 \mathrm{a}$ & $10.83 \mathrm{a}$ & $0.253 \mathrm{a}$ & $0.225 \mathrm{a}$ & $0.143 \mathrm{~b}$ & $1.810 \mathrm{a}$ & $12.63 \mathrm{a}$ \\
\hline 秀水 134 & NT & $1.06 \mathrm{a}$ & $0.96 \mathrm{a}$ & $0.56 \mathrm{a}$ & $6.53 \mathrm{~b}$ & $8.97 \mathrm{~b}$ & $0.233 \mathrm{a}$ & $0.211 \mathrm{a}$ & $0.123 \mathrm{a}$ & $1.442 \mathrm{~b}$ & $11.71 \mathrm{~b}$ \\
\hline Xiushui 134 & HT & $0.92 \mathrm{~b}$ & $0.97 \mathrm{a}$ & $0.52 \mathrm{~b}$ & $7.26 \mathrm{a}$ & $9.61 \mathrm{a}$ & $0.186 \mathrm{~b}$ & $0.196 \mathrm{~b}$ & $0.103 \mathrm{~b}$ & $1.466 \mathrm{a}$ & $14.23 \mathrm{a}$ \\
\hline 秀水 09 & NT & $1.01 \mathrm{a}$ & $1.07 \mathrm{~b}$ & $0.64 \mathrm{a}$ & $6.47 \mathrm{~b}$ & $9.38 \mathrm{~b}$ & $0.224 \mathrm{a}$ & $0.237 \mathrm{a}$ & $0.142 \mathrm{a}$ & $1.433 \mathrm{a}$ & $10.11 \mathrm{~b}$ \\
\hline Xiushui 09 & HT & $0.98 \mathrm{a}$ & $1.12 \mathrm{a}$ & $0.57 \mathrm{~b}$ & $7.24 \mathrm{a}$ & $10.15 \mathrm{a}$ & $0.195 \mathrm{~b}$ & $0.221 \mathrm{~b}$ & $0.113 \mathrm{~b}$ & $1.439 \mathrm{a}$ & $12.70 \mathrm{a}$ \\
\hline \multirow[t]{2}{*}{9311} & NT & $0.89 \mathrm{a}$ & $0.97 \mathrm{a}$ & $0.57 \mathrm{a}$ & $7.32 \mathrm{~b}$ & $10.67 \mathrm{~b}$ & $0.209 \mathrm{~b}$ & $0.228 \mathrm{a}$ & $0.130 \mathrm{a}$ & $1.724 \mathrm{a}$ & $12.84 \mathrm{~b}$ \\
\hline & HT & $0.88 \mathrm{a}$ & $1.02 \mathrm{a}$ & $0.58 \mathrm{a}$ & $8.01 \mathrm{a}$ & $11.02 \mathrm{a}$ & $0.224 \mathrm{a}$ & $0.216 \mathrm{~b}$ & $0.120 \mathrm{a}$ & $1.695 \mathrm{a}$ & $13.81 \mathrm{a}$ \\
\hline 角优 2640 & NT & $0.92 \mathrm{~b}$ & $1.09 \mathrm{a}$ & $0.65 \mathrm{a}$ & $7.13 \mathrm{~b}$ & $9.96 \mathrm{~b}$ & $0.212 \mathrm{a}$ & $0.251 \mathrm{a}$ & $0.150 \mathrm{a}$ & $1.642 \mathrm{a}$ & $10.97 \mathrm{~b}$ \\
\hline Yongyou 2640 & HT & $0.99 \mathrm{a}$ & $1.18 \mathrm{a}$ & $0.54 \mathrm{~b}$ & $7.46 \mathrm{a}$ & $10.35 \mathrm{a}$ & $0.216 \mathrm{a}$ & $0.258 \mathrm{a}$ & $0.123 \mathrm{~b}$ & $1.632 \mathrm{a}$ & $13.81 \mathrm{a}$ \\
\hline
\end{tabular}

NT 和 HT 分别表示灌浆结实期的常温处理和高温处理; 在同一列的相同品种中, 小写字母相同者表示两个温度处理间(NT 和 HT)的差 异末达到统计显著水平。

NT and HT mean normal temperature treatment and high temperature treatment during grain filling, respectively. Data followed by the same small letter in the same column indicate the insignificant difference $(P<0.05)$ between NT and HT for the same rice cultivar . 
处理 $(\mathrm{MN})$ 间差异未到达统计显著水平。氮素穗肥处 理对水稻单位籽粒蛋白绝对含量 $\left(\mathrm{mg} \mathrm{grain}^{-1}\right)$ 的影响 与其百分相对含量 $(\%)$ 相似, 总体趋势表现为 $\mathrm{HN}>$ $\mathrm{MN}>\mathrm{LN}$ ，但 $\mathrm{HN}$ 与 $\mathrm{MN}$ 两个处理之间的差异幅度相
对较小。其中, 部分品种在 $\mathrm{HN}$ 和 $\mathrm{MN}$ 两个处理间 的单位籽粒醇溶蛋白和谷蛋白含量 $\left(\mathrm{mg} \operatorname{grain}^{-1}\right)$ 差异 末达统计显著水平(表 2)。此外，与不施氮对照 $(\mathrm{LN})$ 相比，增施氮肥( HN 和 $\mathrm{MN})$ 引起稻米醇溶蛋白含量

A

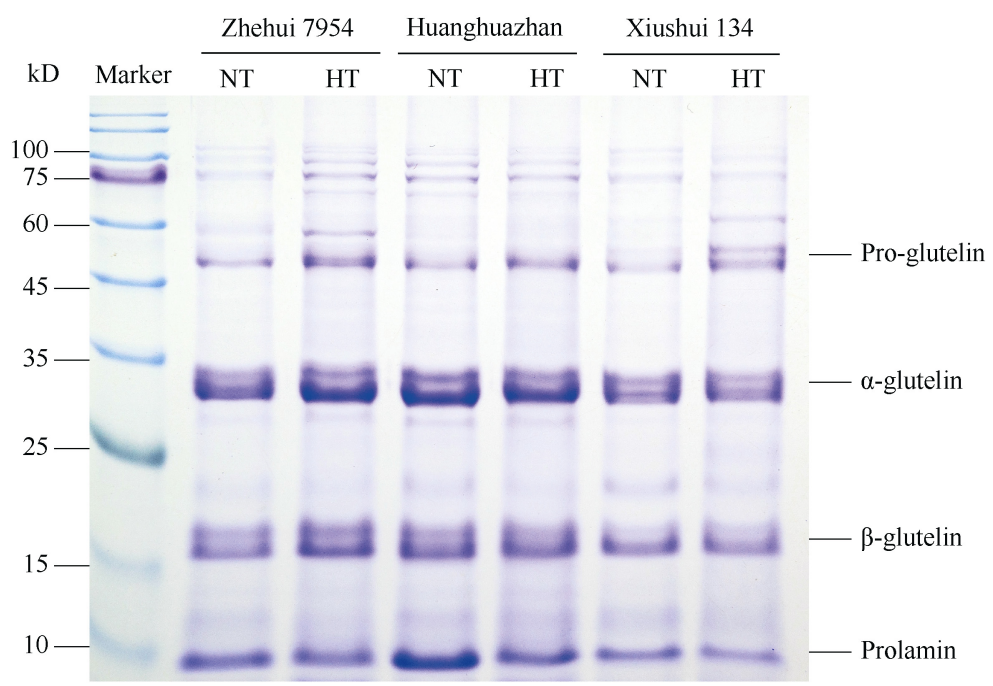

$\mathrm{B}$
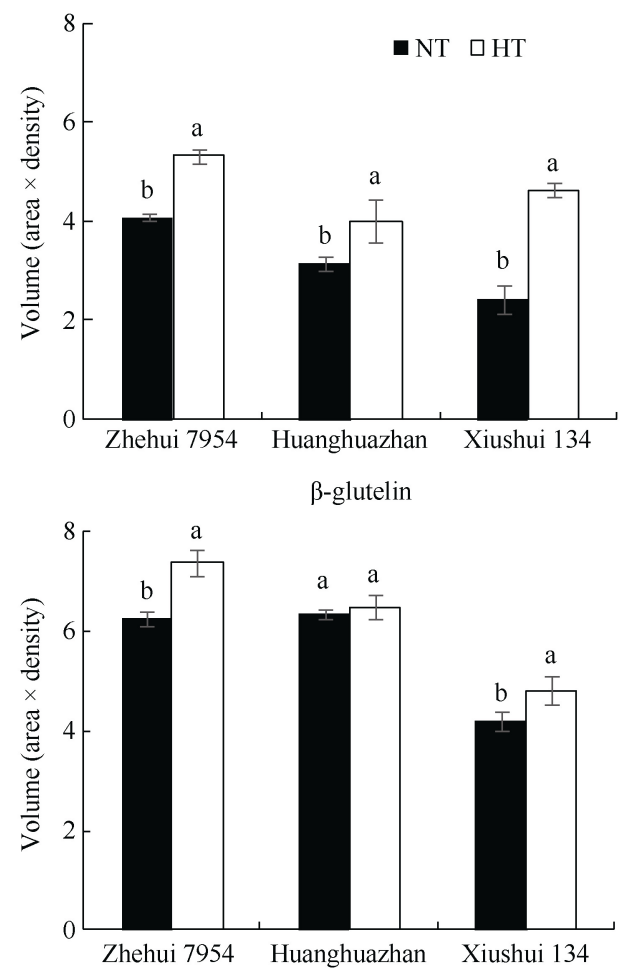

$\alpha$-glutelin

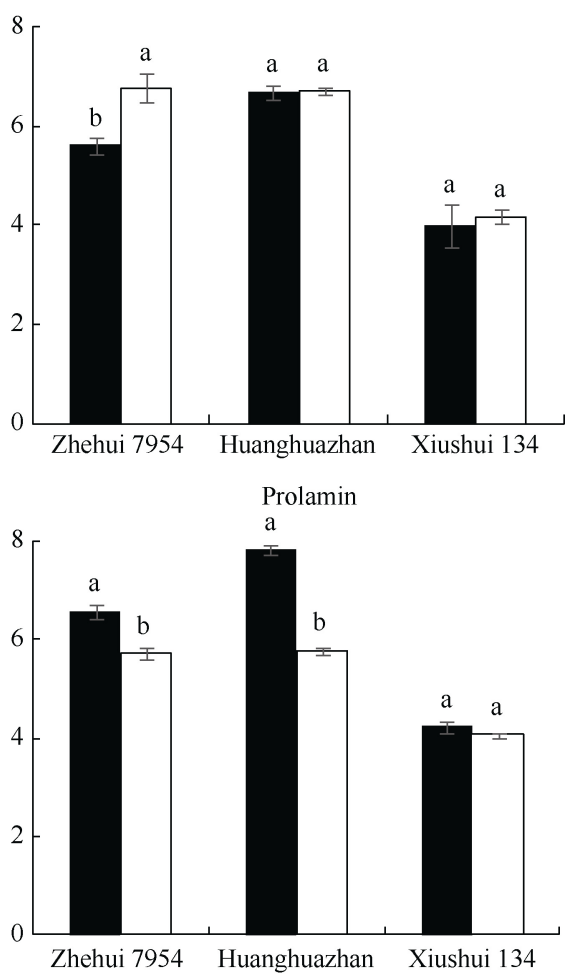

图 1 不同温度处理下水稻籽粒㫟藏蛋白 SDS-PAGE 及其主要蛋白条带的相对光密度差异

Fig. 1 Differences in SDS-PAGE and relative optical density of storage protein between two temperature treatments

NT 和 HT 分别表示灌浆结实期的常温处理和高温处理; A 和 B 分别表示水稻籽粒咜藏蛋白 SDS-PAGE 图和主要蛋白条带的相对光密 度图; 同一品种中的 2 个温度处理间相比, 小写字母相同者表示 2 个温度处理间(NT 和 HT)的差异未达到统计显著水平 $(P<0.05)$; 垂 直棒代表 3 次生物学重复的标准误差。

NT and HT mean normal temperature regime and high temperature regime during grain filling, respectively. A and B mean SDS-PAGE and relative optical density of storage protein, respectively. For a same rice cultivar, bars indexed with the same small letters are not significantly different $(P<0.05)$ between NT and HT. Error bars represent SD values of three biological replicates. 
表 2 不同施氮水平下水稻籽粒蛋白含量及其组分差异

Table 2 Differences in total protein and its component contents in rice kernels among different $\mathrm{N}$ treatment

\begin{tabular}{|c|c|c|c|c|c|c|c|c|c|c|c|}
\hline \multirow[b]{2}{*}{$\begin{array}{c}\text { 品种 } \\
\text { Cultivar }\end{array}$} & \multirow[b]{2}{*}{$\begin{array}{c}\text { 处理 } \\
\text { Treatment }\end{array}$} & \multicolumn{5}{|c|}{ 相对含量 Relative content (\%) } & \multicolumn{5}{|c|}{ 绝对含量 Accumulation amount (mg grain ${ }^{-1}$ ) } \\
\hline & & $\begin{array}{l}\text { 清蛋白 } \\
\text { Albumin }\end{array}$ & $\begin{array}{l}\text { 球蛋白 } \\
\text { Globulin }\end{array}$ & $\begin{array}{c}\text { 醇溶 } \\
\text { 蛋白 } \\
\text { Prolamin }\end{array}$ & $\begin{array}{l}\text { 谷蛋白 } \\
\text { Glutelin }\end{array}$ & $\begin{array}{c}\text { 总蛋白 } \\
\text { Total } \\
\text { protein }\end{array}$ & $\begin{array}{l}\text { 清蛋白 } \\
\text { Albumin }\end{array}$ & $\begin{array}{l}\text { 球蛋白 } \\
\text { Globulin }\end{array}$ & $\begin{array}{l}\text { 醇溶蛋白 } \\
\text { Prolamin }\end{array}$ & $\begin{array}{l}\text { 谷蛋白 } \\
\text { Glutelin }\end{array}$ & $\begin{array}{l}\text { 谷/醇比 } \\
\text { Glu/Prol }\end{array}$ \\
\hline \multirow{3}{*}{$\begin{array}{c}\text { 浙恢 } 7954 \\
\text { Zhehui7954 }\end{array}$} & LN & $0.87 \mathrm{~b}$ & $0.83 \mathrm{~b}$ & $0.53 \mathrm{~b}$ & $6.71 \mathrm{c}$ & $8.87 \mathrm{c}$ & $0.197 \mathrm{~b}$ & $0.188 \mathrm{c}$ & $0.120 \mathrm{~b}$ & $1.524 \mathrm{c}$ & $12.66 \mathrm{~b}$ \\
\hline & $\mathrm{MN}$ & $0.89 \mathrm{~b}$ & $1.06 \mathrm{a}$ & $0.58 \mathrm{a}$ & $7.39 \mathrm{~b}$ & $10.57 \mathrm{a}$ & $0.206 \mathrm{ab}$ & $0.246 \mathrm{a}$ & $0.137 \mathrm{a}$ & $1.714 \mathrm{~b}$ & $12.53 \mathrm{~b}$ \\
\hline & $\mathrm{HN}$ & $1.03 \mathrm{a}$ & $0.97 \mathrm{~b}$ & $0.61 \mathrm{a}$ & $8.06 \mathrm{a}$ & $10.81 \mathrm{a}$ & $0.228 \mathrm{a}$ & $0.215 \mathrm{~b}$ & $0.135 \mathrm{a}$ & $1.786 \mathrm{a}$ & $13.21 \mathrm{a}$ \\
\hline \multirow{3}{*}{$\begin{array}{c}\text { 黄华占 } \\
\text { Huanghuazhan }\end{array}$} & $\mathrm{LN}$ & $0.86 \mathrm{~b}$ & $0.92 \mathrm{~b}$ & $0.66 \mathrm{~b}$ & $7.47 \mathrm{~b}$ & $9.43 \mathrm{~b}$ & $0.187 \mathrm{c}$ & $0.200 \mathrm{~b}$ & $0.144 \mathrm{~b}$ & $1.626 \mathrm{~b}$ & $11.57 \mathrm{~b}$ \\
\hline & MN & $1.02 \mathrm{a}$ & $1.11 \mathrm{a}$ & $0.68 \mathrm{ab}$ & $8.08 \mathrm{a}$ & $11.06 \mathrm{a}$ & $0.226 \mathrm{a}$ & $0.245 \mathrm{a}$ & $0.151 \mathrm{a}$ & $1.790 \mathrm{a}$ & $11.93 \mathrm{a}$ \\
\hline & $\mathrm{HN}$ & $0.98 \mathrm{a}$ & $1.06 \mathrm{a}$ & $0.71 \mathrm{a}$ & $8.12 \mathrm{a}$ & $11.18 \mathrm{a}$ & $0.211 \mathrm{~b}$ & $0.228 \mathrm{ab}$ & $0.153 \mathrm{a}$ & $1.747 \mathrm{a}$ & $11.66 \mathrm{~b}$ \\
\hline \multirow{3}{*}{$\begin{array}{c}\text { 秀水 } 134 \\
\text { Xiushui } 134\end{array}$} & $\mathrm{LN}$ & $0.87 \mathrm{~b}$ & $0.91 \mathrm{~b}$ & $0.56 \mathrm{~b}$ & $5.75 \mathrm{c}$ & $8.57 \mathrm{~b}$ & $0.184 \mathrm{~b}$ & $0.192 \mathrm{~b}$ & $0.110 \mathrm{~b}$ & $1.320 \mathrm{~b}$ & $11.16 \mathrm{~b}$ \\
\hline & MN & $0.91 \mathrm{~b}$ & $1.07 \mathrm{a}$ & $0.63 \mathrm{a}$ & $6.91 \mathrm{~b}$ & $10.24 \mathrm{a}$ & $0.189 \mathrm{~b}$ & $0.222 \mathrm{a}$ & $0.131 \mathrm{a}$ & $1.538 \mathrm{a}$ & $11.76 \mathrm{a}$ \\
\hline & HN & $1.12 \mathrm{a}$ & $1.08 \mathrm{a}$ & $0.66 \mathrm{a}$ & $7.17 \mathrm{a}$ & $10.53 \mathrm{a}$ & $0.223 \mathrm{a}$ & $0.215 \mathrm{ab}$ & $0.132 \mathrm{a}$ & $1.530 \mathrm{a}$ & $11.62 \mathrm{a}$ \\
\hline \multirow{3}{*}{$\begin{array}{c}\text { 秀水 } 09 \\
\text { Xiushui } 09\end{array}$} & $\mathrm{LN}$ & $0.92 \mathrm{~b}$ & $0.93 \mathrm{c}$ & $0.51 \mathrm{c}$ & $6.32 \mathrm{c}$ & $9.09 \mathrm{c}$ & $0.204 \mathrm{~b}$ & $0.206 \mathrm{~b}$ & $0.113 \mathrm{~b}$ & $1.384 \mathrm{c}$ & $12.21 \mathrm{~b}$ \\
\hline & MN & $0.90 \mathrm{~b}$ & $1.07 \mathrm{~b}$ & $0.57 \mathrm{~b}$ & $7.04 \mathrm{~b}$ & $9.85 \mathrm{~b}$ & $0.201 \mathrm{~b}$ & 0.239 a & 0.127 a & $1.663 \mathrm{~b}$ & $13.05 \mathrm{a}$ \\
\hline & $\mathrm{HN}$ & $1.06 \mathrm{a}$ & $1.14 \mathrm{a}$ & $0.64 \mathrm{a}$ & $7.76 \mathrm{a}$ & $10.98 \mathrm{a}$ & $0.223 \mathrm{a}$ & $0.240 \mathrm{a}$ & $0.130 \mathrm{a}$ & $1.716 \mathrm{a}$ & $13.16 \mathrm{a}$ \\
\hline
\end{tabular}

LN、MN 和 $\mathrm{HN}$ 分别表示低氮 $\left(0 \mathrm{~kg} \mathrm{hm}^{-2}\right)$ 、中氮 $\left(180 \mathrm{~kg} \mathrm{hm}^{-2}\right)$ 和高氮 $\left(300 \mathrm{~kg} \mathrm{hm}^{-2}\right)$ 处理水平; 在同一列的相同品种中, 小写字母相同者 表示不同氮处理水平间的差异未达到统计显著水平 $(P<0.05)$ 。

LN, MN, and HN mean low nitrogen $\left(0 \mathrm{~kg} \mathrm{hm}^{-2}\right)$, medium nitrogen $\left(180 \mathrm{~kg} \mathrm{hm}^{-2}\right)$, and high nitrogen $\left(300 \mathrm{~kg} \mathrm{hm}^{-2}\right)$ levels, respectively. Data followed by the same small letter in same column indicate the insignificant difference $(P<0.05)$ between different $\mathrm{N}$ treatments for the same rice cultivar.

(包括百分相对含量与单位籽粒绝对含量)的显著提 高, 这与醇溶蛋白含量受高温处理影响所表现出的 下降趋势有明显差别。与高温处理相似, 增施氮肥 引起水稻籽粒中的谷蛋白/醇溶蛋白比值上升(表 2)。 但从变化幅度看, 同一品种的谷蛋白/醇溶蛋白比 值在不同氮素处理下的差异范围大致在 $0.46 \sim 0.95$ 之间(表 2), 远低于其在不同温度处理(HT 与 NT) 间的差异幅度(表 1)。这说明氮素穗肥对水稻籽粒 谷蛋白/醇溶蛋白比值的影响程度相对小于高温 处理。

利用 SDS-PAGE 对不同氮处理水平下籽粒咜藏 蛋白亚基组成的检测表明(图 2)，低氮处理下几个主 要蛋白亚基条带(包括 pro-glutelin、 $\alpha$-glutelin、 $\beta$-glutelin 和 prolamin)的相对亮度均弱于其同一品种 的高氮 $(\mathrm{HN})$ 和中氮 $(\mathrm{MN})$ 处理(图 2-A)。光密度扫描 结果表明, 施氮处理(HT 和 MN)对谷蛋白亚基组成 的影响不明显, 谷蛋白的 $57 \mathrm{kD}$ 前体亚基 (proglutelin)、37 kD 酸性亚基( $\alpha$-glutelin)和 $22 \mathrm{kD}$ 碱性 亚基( $\beta$-glutelin)在高氮( $\mathrm{HN})$ 和中氮( $\mathrm{MN}$ )的含量均显 著高于其低氮处理(LN)。与此同时, 醇溶蛋白亚基 含量在高氮处理 $(\mathrm{HN})$ 下也呈上升趋势。说明高氮处
理虽然会引起水稻籽粒谷蛋白和醇溶蛋白含量的上 升, 但对谷蛋白亚基的积累形态影响并不明显。

2.3 温氮两因素处理对水稻籽粒蛋白含量和组 分的影响

对不同温氮处理下水稻籽粒 4 种蛋白组分和总 蛋白含量的比较可知 (表 3), 高氮 (HN)+高温(HT2) 处理组合下的籽粒谷蛋白和总蛋白含量 $(\%)$ 明显高 于高氮 $(\mathrm{HN})+$ 常温 $(\mathrm{NT})$ 和低氮 $(\mathrm{LN})+$ 高温 $(\mathrm{HT} 2)$ 等处 理组合, 但高温(HT2)+高氮(HN)处理组合下的单位 籽粒谷蛋白的绝对含量 $\left(\mathrm{mg} \mathrm{grain}^{-1}\right)$ 却低于高氮 $(\mathrm{HN})+$ 常温 $(\mathrm{NT})$ 处理组合, 这说明高氮 + 高温处理 $(\mathrm{HN}+\mathrm{HT} 2)$ 并不会引起谷蛋白绝对含量 $\left(\mathrm{mg} \operatorname{grain}^{-1}\right)$ 的进一步提升。此外, 在低氮 $(\mathrm{LN})$ 和高氮 $(\mathrm{HN})$ 水平 下, 高温处理均会引起水稻籽粒醇溶蛋白含量(相对 百分含量和单位籽粒绝对含量)的较明显下降和谷 蛋白/醇溶蛋白的比值上升, 且其绝对含量 $(\mathrm{mg}$ grain $^{-1}$ )在 HT2 处理下的下降或上升幅度大于 HT1 处理。同一温度处理下的不同氮水平相比, 籽粒总 蛋白、清蛋白、球蛋白、醇溶蛋白和谷蛋白在高氮 水平 $(\mathrm{HN})$ 下的相对含量 $(\%)$ 和绝对含量 $\left(\mathrm{mg}\right.$ grain $\left.^{-1}\right)$ 均显著高于其相应的低氮(LN)处理(表 3)。 

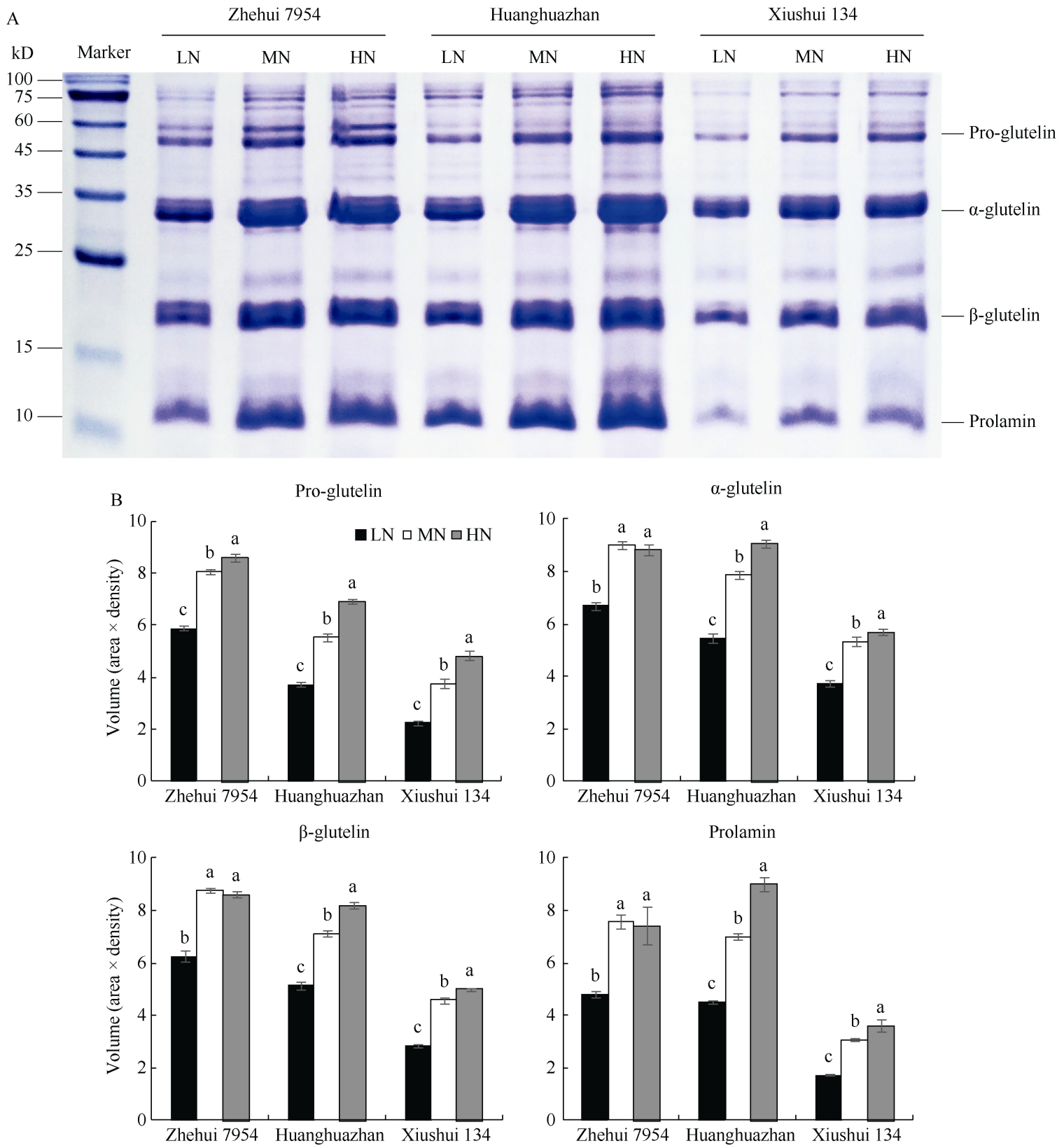

图 2 不同施氮水平下水稻籽粒䛎藏蛋白 SDS-PAGE 及其主要蛋白条带的相对光密度差异

Fig. 2 Differences in SDS-PAGE and relative optical density of storage protein among three $\mathbf{N}$ treatments

$\mathrm{LN} 、 \mathrm{MN}$ 和 $\mathrm{HN}$ 分别表示低氮 $\left(0 \mathrm{~kg} \mathrm{hm}^{-2}\right)$ 、中氮 $\left(180 \mathrm{~kg} \mathrm{hm}^{-2}\right)$ 和高氮 $\left(300 \mathrm{~kg} \mathrm{hm}^{-2}\right)$ 处理水平; $\mathrm{A}$ 和 $\mathrm{B}$ 分别表示水稻籽粒咜藏蛋白 SDS-PAGE 图和主要蛋白条带的相对光密度图; 相同水稻品种, 小写字母相同者表示不同氮处理水平间的差异未达到统计显著水 平 $(P<0.05)$; 垂直棒代表 3 次生物学重复的标准误差。

$\mathrm{LN}, \mathrm{MN}$, and HN mean low nitrogen $\left(0 \mathrm{~kg} \mathrm{hm}^{-2}\right)$, medium nitrogen $\left(180 \mathrm{~kg} \mathrm{hm}^{-2}\right)$, and high nitrogen $\left(300 \mathrm{~kg} \mathrm{hm}^{-2}\right)$ levels, respectively. A and B mean SDS-PAGE and relative optical density of storage protein, respectively. Bars indexed with the same small letters are not significantly different $(P<0.05)$ between different $\mathrm{N}$ levels for the same rice cultivar; Error bars represented SD values of three biological replicates.

对不同氮(素)×温(度)处理下籽粒咜藏蛋白亚基 组成的 SDS-PAGE 检测结果(图 3)表明, 在低氮水平 下, 高温处理(HT1 和 HT2)会引起籽粒谷蛋白的 $57 \mathrm{kD}$ 前体亚基(pro-glutelin)、37 $\mathrm{kD}$ 酸性亚基 $(\alpha$ glutelin)和 $22 \mathrm{kD}$ 碱性亚基( $\beta$-glutelin)含量显著升高, 但在高氮水平下, 高温处理(HT1 和 HT2)的 $37 \mathrm{kD}$ 酸
性亚基( $\alpha$-glutelin)和 $22 \mathrm{kD}$ 碱性亚基( $\beta$-glutelin)含量却 低于常温处理(NT)。这说明灌浆温度对籽粒谷蛋白含量 的影响可能与氮营养供应状况有关, 温度与氮肥对稻 米谷蛋白及其亚基组分的影响存在一定程度的互作效 应。对醇溶蛋白而言，在低氮水平 $(\mathrm{LN})$ 和高氮水平 $(\mathrm{HN})$ 下, 高温处理均会引起其含量的明显降低(图 3-B)。 
表 3 温氮处理下水稻籽粒蛋白及其组分的含量差异

Table 3 Differences of grain protein components and contents in rice under different temperature and different $\mathrm{N}$ levels

\begin{tabular}{|c|c|c|c|c|c|c|c|c|c|c|c|}
\hline \multirow[b]{2}{*}{$\begin{array}{l}\text { 氮水平 } \\
\mathrm{N} \text { level }\end{array}$} & \multirow[b]{2}{*}{$\begin{array}{c}\text { 温度处理 } \\
\text { Temperature } \\
\text { treatment }\end{array}$} & \multicolumn{5}{|c|}{ 相对含量 Relative content (\%) } & \multicolumn{5}{|c|}{ 绝对含量 Accumulation amount (mg grain ${ }^{-1}$ ) } \\
\hline & & $\begin{array}{c}\text { 清蛋白 } \\
\text { Albumin }\end{array}$ & $\begin{array}{l}\text { 球蛋白 } \\
\text { Globulin }\end{array}$ & $\begin{array}{c}\text { 醇溶蛋白 } \\
\text { Prolamin }\end{array}$ & $\begin{array}{l}\text { 谷蛋白 } \\
\text { Glutelin }\end{array}$ & $\begin{array}{c}\text { 总蛋白 } \\
\text { Total } \\
\text { protein }\end{array}$ & $\begin{array}{c}\text { 清蛋白 } \\
\text { Albumin }\end{array}$ & $\begin{array}{l}\text { 球蛋白 } \\
\text { Globulin }\end{array}$ & $\begin{array}{c}\text { 醇溶蛋白 } \\
\text { Prolamin }\end{array}$ & $\begin{array}{c}\text { 谷蛋白 } \\
\text { Glutelin }\end{array}$ & $\begin{array}{l}\text { 谷/醇比 } \\
\text { Glu/prol }\end{array}$ \\
\hline \multirow[t]{4}{*}{$\mathrm{LN}$} & NT & $0.81 \mathrm{~b}$ & $0.84 \mathrm{~b}$ & $0.53 \mathrm{a}$ & $6.45 \mathrm{~b}$ & $8.52 \mathrm{c}$ & $0.19 \mathrm{a}$ & $0.19 \mathrm{a}$ & $0.12 \mathrm{a}$ & $1.49 \mathrm{a}$ & $12.17 \mathrm{c}$ \\
\hline & HT1 & $0.87 \mathrm{~b}$ & $0.95 \mathrm{a}$ & $0.51 \mathrm{a}$ & $7.03 \mathrm{a}$ & $9.29 \mathrm{~b}$ & $0.19 \mathrm{a}$ & $0.21 \mathrm{a}$ & $0.11 \mathrm{a}$ & $1.52 \mathrm{a}$ & $13.48 \mathrm{~b}$ \\
\hline & HT2 & $1.09 \mathrm{a}$ & $1.03 \mathrm{~b}$ & $0.46 \mathrm{~b}$ & $6.98 \mathrm{a}$ & $9.41 \mathrm{a}$ & $0.20 \mathrm{a}$ & $0.20 \mathrm{a}$ & $0.09 \mathrm{~b}$ & $1.38 \mathrm{~b}$ & $15.17 \mathrm{a}$ \\
\hline & 平均 Mean & $0.92 \mathrm{~B}$ & $0.94 \mathrm{~B}$ & $0.50 \mathrm{~B}$ & $6.80 \mathrm{~B}$ & $9.04 \mathrm{~B}$ & $0.19 \mathrm{~B}$ & $0.20 \mathrm{~B}$ & $0.11 \mathrm{~B}$ & $1.47 \mathrm{~B}$ & $13.63 \mathrm{~A}$ \\
\hline \multirow[t]{4}{*}{$\mathrm{HN}$} & NT & $0.93 \mathrm{~b}$ & $1.02 \mathrm{~b}$ & $0.61 \mathrm{a}$ & $7.15 \mathrm{~b}$ & $9.77 \mathrm{~b}$ & $0.21 \mathrm{a}$ & $0.23 \mathrm{ab}$ & $0.14 \mathrm{a}$ & $1.64 \mathrm{a}$ & $11.72 \mathrm{~b}$ \\
\hline & HT1 & $0.91 \mathrm{a}$ & $0.97 \mathrm{a}$ & $0.56 \mathrm{~b}$ & $7.23 \mathrm{~b}$ & $10.24 \mathrm{a}$ & $0.21 \mathrm{a}$ & $0.22 \mathrm{~b}$ & $0.13 \mathrm{ab}$ & $1.66 \mathrm{a}$ & $13.15 \mathrm{a}$ \\
\hline & HT2 & $1.07 \mathrm{a}$ & $1.18 \mathrm{a}$ & $0.58 \mathrm{ab}$ & $7.84 \mathrm{a}$ & $10.59 \mathrm{a}$ & $0.22 \mathrm{a}$ & $0.24 \mathrm{a}$ & $0.12 \mathrm{~b}$ & $1.58 \mathrm{~b}$ & $13.75 \mathrm{a}$ \\
\hline & 平均 Mean & $0.97 \mathrm{~A}$ & $1.06 \mathrm{~A}$ & $0.58 \mathrm{~A}$ & $7.41 \mathrm{~A}$ & $10.20 \mathrm{~A}$ & $0.21 \mathrm{~A}$ & $0.23 \mathrm{~A}$ & $0.13 \mathrm{~A}$ & $1.63 \mathrm{~A}$ & $12.84 \mathrm{~B}$ \\
\hline 氮肥效应 & Nitrogen & $* *$ & $* *$ & $* *$ & $* *$ & $* *$ & $* *$ & $* *$ & $* *$ & $* *$ & $* *$ \\
\hline 温度效应 & Temperature & $* *$ & $* *$ & $* *$ & $* *$ & $* *$ & $\mathrm{~ns}$ & $*$ & $* *$ & $* *$ & $* *$ \\
\hline 氮肥×温度 & & $* *$ & $* *$ & $* *$ & $* *$ & $* *$ & $\mathrm{~ns}$ & $\mathrm{~ns}$ & $\mathrm{~ns}$ & $* *$ & $* *$ \\
\hline Nitrogen $\times$ & temperature & & & & & & & & & & \\
\hline
\end{tabular}

$\mathrm{LN}$ 和 $\mathrm{HN}$ 分别表示高氮和低氮水平; NT、HT1 和 HT2 分别表示常温处理(日均温度 $23^{\circ} \mathrm{C}$ )、高温 $\mathrm{I}$ 处理(日均温度 $\left.30^{\circ} \mathrm{C}\right)$ 和高温 $\mathrm{II}$ 处理 (日均温度 $34^{\circ} \mathrm{C}$ )。大写字母相同者表示不同氮肥处理间的差异未达 $1 \%$ 统计显著水平; 小写字母相同者表示在同一氮肥处理下不同温 度处理间的差异未达 5\%统计显著水平; **和*分别表示方差分析在 0.01 和 0.05 水平上效应显著, NS 表示方差分析不显著。

$\mathrm{LN}$ and $\mathrm{HN}$ mean low nitrogen and high nitrogen levels, respectively; NT, HT1, and HT2 mean normal temperature regime $\left(23^{\circ} \mathrm{C}\right), \mathrm{HT} 1\left(30^{\circ} \mathrm{C}\right)$ and HT2 $\left(34^{\circ} \mathrm{C}\right)$, respectively. Data followed by the same capital letter in same column are not significantly different (1\% level) for two nitrogen treatments; Data followed by the same small letter in same column are not significantly different (5\% level) for different temperature treatments under the same nitrogen treatment; ** and * indicate the significance at the 0.01 and 0.05 levels, respectively; NS means no significant difference based on the analysis of variance.

\section{3 讨论}

关于灌浆结实期温度对稻米蛋白质含量影响, 现已不乏报道, 但研究结论不- ${ }^{[15,18,24-25]}$ 。多数研究 报道认为, 灌浆结实高温或夜间增温会引起稻米粗 蛋白含量提高 ${ }^{[15,22-24]}$, 但周广洽等 ${ }^{[26]}$ 认为, 灌浆结 实期温度过高或过低都会引起稻米蛋白质含量下 降。据 Krishman 等 ${ }^{[15]}$ 报道, 灌浆温度对稻米蛋白质 含量的影响因品种而异, 大多数品种蛋白质含量与 结实期温度正相关，但也有部分品种的蛋白质含量 与灌浆温度相关不显著或呈负相关。Lin 等 ${ }^{[18]}$ 认为, 稻米蛋白质含量在高温胁迫下增加的原因主要是籽 粒粗蛋白占籽粒总干重的相对比值增加, 且高温胁 迫会导致籽粒灌浆后期咜藏蛋白积累量减少 ${ }^{[27]}$ 。本 研究中, 稻米谷蛋白和总蛋白的相对含量 $(\%)$ 在高 温处理下呈显著上升趋势, 这与前人的大多数研究 结果基本一致。但从单位籽粒中积累的蛋白绝对量 看, 除浙恢 7954 和秀水 134 之外, 其余 4 个品种单 位籽粒中所积累的谷蛋白的绝对含量在高温处理
下并没有表现出十分明显的上升趋势(表 1)。据前人 研究报道, 水稻籽粒淀粉合成积累量在高温胁迫下 显著降低、糊粉层占淀粉层的相对比例明显提高 ${ }^{[15,22]}$, 高温胁迫对灌浆籽粒中糖转运和淀粉合成代谢相关 基因转录表达水平的影响幅度比咜藏蛋白合成代谢 相关基因明显 ${ }^{[28]}$ 。Yamakawa 等 ${ }^{[29]}$ 研究表明, 水稻胚 乳中的谷蛋白、醇溶蛋白和球蛋白类基因在高温处 理下多呈下调表达特征。由此笔者推测, 灌浆结实 期高温引起稻米蛋白含量 $(\%)$ 上升的原因, 在很大 程度上与高温胁迫下的淀粉积累量下降和䛎藏蛋白 占籽粒干重的相对比例增加所引起的“浓缩效应”有 关, 籽粒干重和淀粉积累量的下降, 是高温处理下 水稻籽粒败藏蛋白的相对含量 (\%)增加的一个重要 因素。此外, 高温胁迫处理不仅影响水稻籽粒的䛎 藏蛋白总量, 而且影响聍藏蛋白的组成及其积累形 态。本文人工气候箱控温试验表明, 不同水稻品种 籽粒中的醇溶蛋白含量在高温处理下均一定程度下 降, 这与马启林等 ${ }^{[25]}$ 的研究结果基本一致。本文 

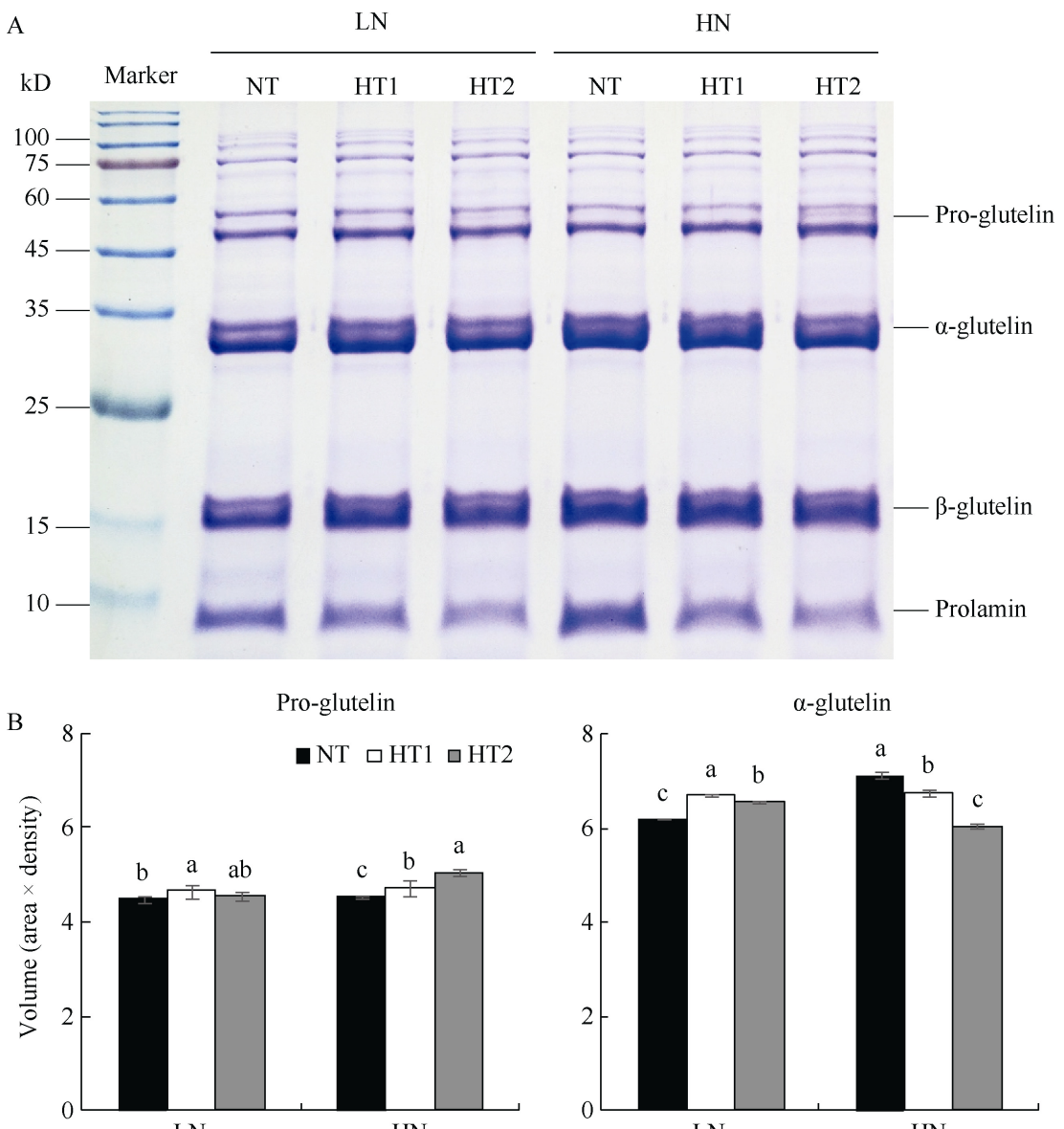

LN $\quad \beta$-glutelin

LN

HN
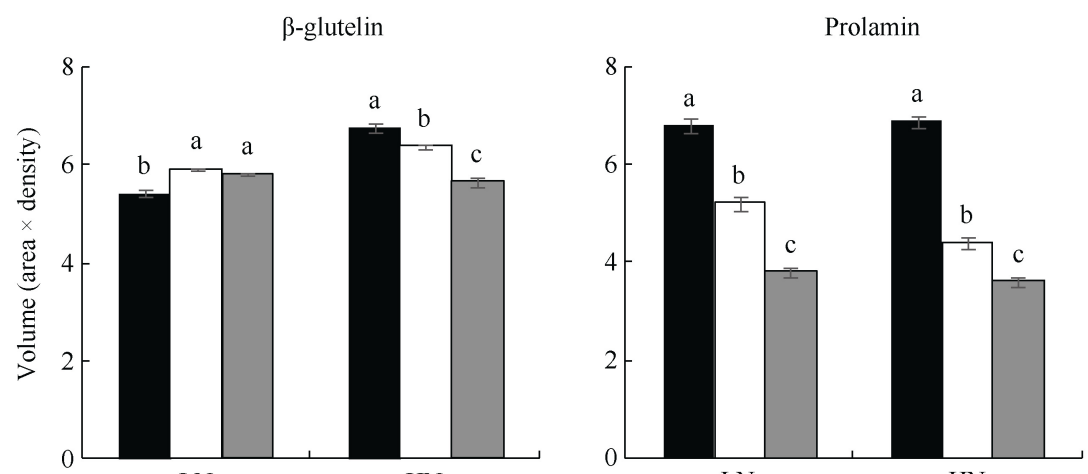

$\mathrm{LN}$

HN

$\mathrm{LN}$

$\mathrm{HN}$

图 3 温氮处理下水稻籽粒㫟藏蛋白的 SDS-PAGE 及其主要蛋白条带的相对光密度差异

Fig. 3 Differences in SDS-PAGE and relative optical density of storage protein treated under different temperature regimes and different $\mathbf{N}$ levels

$\mathrm{LN}$ 和 HN 分别表示高氮和低氮水平; NT、HT1 和 HT2 分别表示常温处理(日均温度 $23^{\circ} \mathrm{C}$ )、高温 $\mathrm{I}$ 处理 $\left(\right.$ 日均温度 $30^{\circ} \mathrm{C}$ )和高温 $\mathrm{II}$ 处理 (日均温度 $\left.34^{\circ} \mathrm{C}\right)$ 。 A 和 B 分别表示水稻籽粒垤藏蛋白 SDS-PAGE 图和主要蛋白条带的相对光密度图。小写字母相同者表示不同处理 水平间的差异未达到统计显著水平 $(P<0.05)$; 垂直棒代表 3 次生物学重复的标准误差。

$\mathrm{LN}$ and HN mean low nitrogen and high nitrogen levels, respectively; NT, HT1, and HT2 mean normal temperature regime $\left(23^{\circ} \mathrm{C}\right), \mathrm{HT} 1\left(30^{\circ} \mathrm{C}\right)$ and HT2 $\left(34^{\circ} \mathrm{C}\right)$, respectively. A and B mean SDS-PAGE and relative optical density of storage protein, respectively. Bars indexed with the same small letters are not significantly different $(P<0.05)$ among different treatments; Error bars represent SD values of three biological replicates.

进一步揭示, 高温处理所引起水稻籽粒醇溶蛋白含 量的下降现象，不仅表现在醇溶蛋白占籽粒干重的 相对含量 $(\%)$ 上，而且也表现在单位籽粒中的醇溶
蛋白的绝对含量 $\left(\mathrm{mg} \operatorname{grain}^{-1}\right)$ 上(表 1)。高温处理在引 起水稻籽粒醇溶蛋白及其 $13 \mathrm{kD}$ 亚基组分含量下降 的同时, 籽粒谷蛋白的 $57 \mathrm{kD}$ 前体亚基(pro-glutelin) 
组分含量有所增加, 而 $37 \mathrm{kD}$ 酸性亚基( $\alpha$-glutelin)和 $22 \mathrm{kD}$ 碱性亚基( $\beta$-glutelin)含量在不同温度处理下的 差异变化因品种而异(图 1)。与之相比, Dou 等 ${ }^{[23]}$ 的 大田增温试验结果表明, 夜间增温会引起稻米粗蛋 白含量增加, 但对稻米各种氨基酸组分的相对比例 影响不大。因此, 灌浆温度对稻米谷蛋白含量的影 响相对较复杂, 可能既与水稻品种本身的谷蛋白含 量高低及其各个亚基组分的比例差异等遗传因素有 关, 也与高温范围或增温幅度等生态因素存在一定 联系。

氮肥水平是影响稻米粗蛋白含量的重要栽培因 素之一。大量研究表明, 增施氮肥或前氮后移会引 起稻米咜藏蛋白含量的较明显增加 ${ }^{[6-10]}$ 。在一定施氮 量范围内, 稻米蛋白含量随氮肥 (尤其是氮素穗肥) 施用量的增加呈上升趋势, 但不同水稻品种的稻米 蛋白含量对氮肥的敏感程度不同, 氮肥施用量过高 会引起部分水稻品种籽粒饱满度下降 ${ }^{[8,10-11]}$ 。在本文 研究结果中, 增施氮肥使水稻籽粒总蛋白及其 4 种 蛋白组分含量 $(\%)$ 显著上升, 这与前人研究结果一 致。本研究利用 SDS-PAGE 对不同氮处理水平下籽 粒咜藏蛋白亚基组成的检测表明，谷蛋白的 $57 \mathrm{kD}$ 前体亚基(pro-glutelin)、37 kD 酸性亚基( $\alpha$-glutelin) 和 $22 \mathrm{kD}$ 碱性亚基( $\beta$-glutelin), 以及醇溶蛋白的 $13 \mathrm{kD}$ 亚基在高氮处理下含量均明显高于其相同品 种的低氮处理(LN)(图 2), 且增施氮肥引起水稻籽粒 谷蛋白/醇溶蛋白的比值有所上升(表 1), 但与灌浆 结实期温度处理相比, 氮肥处理对谷蛋白各个亚基 的积累形态及其相对比例影响不甚明显, 且同一品 种在不同氮肥处理的谷蛋白/醇溶蛋白比值的变化 幅度也没有高温处理对两者比值的影响程度大。值 得关注的是, 增施氮肥( $\mathrm{HN}$ 和 $\mathrm{MN})$ 会引起稻米醇溶 蛋白含量的显著提高, 这与醇溶蛋白受高温处理影 响所表现出的下降趋势有明显不同, 这也是高温处 理有别于高氮处理对稻米䛎藏蛋白组分影响的一个 重要特点。据前人研究报道, 醇溶蛋白存在于蛋白 体 I (PB-I), 球蛋白和谷蛋白储存于蛋白体 II (PB-II) 中 $^{[13,21,30]}$ 。其中, 富含谷蛋白的 PB-II 蛋白体易于消 化, 对食味负面效应小, 而以醇溶蛋白为主的 PB-I 对蛋白分解酶具有较强的抵抗力, 可能是稻米蛋白 质影响米饭食味的一个重要因素 ${ }^{[30-31]}$ 。但在本研究 中, 增施氮肥会引起稻米中的醇溶蛋白含量上升, 而稻米醇溶蛋白含量在高温处理下呈下降趋势, 且 同一品种在高氮处理 $(\mathrm{HN})$ 下的谷蛋白/醇溶蛋白比
值还略高于其低氮处理(LN)和中氮处理(MN)(表 1 和表 2)。因此，尽管稻米蛋白含量及其组分变化会 对稻米蒸煮食味品质产生明显影响, 但稻米食味品 质与咜藏蛋白含量及组分间的关系可能较复杂, 尤 其是灌浆结实期高温造成的稻米食味品质下降现象, 实际上并不是高温胁迫下籽粒醇溶蛋白含量升高所 引起的。

随全球气候的变暖, 水稻高温危害及其栽培措 施缓解问题正日益引起人们关注 ${ }^{[32]}$ 。据前人研究报 道, 合理氮素穗粒肥可减轻或缓解高温对水稻灌浆 结实的胁迫伤害 ${ }^{[33-35]}$ 。段骅等 ${ }^{[36]}$ 认为, 在高温胁迫 下适当增施氮肥可提高水稻的结实率和千粒重, 减 轻高温对产量和稻米品质的不利影响。吴翠平等 ${ }^{[37]}$ 研究表明, 在基追比例 1：1 的基础上增大拔节期氮 素追施比例, 能显著提高小麦常温和高温胁迫下籽 粒产量, 缓解高温胁迫对小麦千粒重和籽粒产量的 不良影响, 但对小麦品质影响不明显。Ito 等 ${ }^{[38]}$ 研究 认为, 高温胁迫会引起小麦籽粒中的淀粉合成受阻, 而适度施氮能通过维持淀粉合成相关酶活性来减轻 高温危害。从而降低高温下稻米严白发生、提高稻 米食味和整精米率。Tang 等 ${ }^{[35]}$ 研究表明, 氮素粒肥 可通过影响稻米淀粉组分及其有关理化特性来缓解 高温胁迫对稻米食味不利效应, 但对于灌浆温度与 氮素穗肥施用对稻米蛋白含量及其组分的影响效应 目前尚不清楚。在本研究中, 高氮 $(\mathrm{HN})+$ 高温 $(\mathrm{HT} 2)$ 处理组合下的稻米谷蛋白和总蛋白含量明显高于高 氮 $(H N)+$ 常温 $(N T)$ 和低氮 $(\mathrm{LN})+$ 高温 $(H T 2)$ 等处理组 合, 这说明高温和高氮对稻米谷蛋白和总蛋白含量 的影响存在着一定程度的“累加”效应，但在高氮处 理 $(\mathrm{HN})$ 下高温引起稻米醇溶蛋白含量的降低幅度相 对小于其相应的低氮处理(LN), 有利于稻米醇溶蛋 白含量在不同温度处理下的相对稳定(表 3 和图 3)。 此外, 本文温氮两因素试验结果表明, 在低氮水平 下, 高温会引起籽粒谷蛋白的 $57 \mathrm{kD}$ 前体亚基、 $37 \mathrm{kD}$ 酸性亚基和 $22 \mathrm{kD}$ 碱性亚基含量显著升高, 而 在高氮水平下, 谷蛋白的上述亚基组分随温度处理 变化却呈相反趋势, 说明灌浆温度对籽粒谷蛋白亚 基组分的影响与氮处理水平有关。对于温度与氮肥 对稻米谷蛋白及其亚基组分影响的互作效应等问题, 尚需今后进一步深入研究。

\section{4 结论}

高温处理和增施氮肥虽然均会引起水稻籽粒总 
蛋白和谷蛋白等组分占籽粒干重相对含量 $(\%)$ 的显 著提升, 但高温处理对单位籽粒中总蛋白与谷蛋白 的绝对含量 $\left(\mathrm{mg}\right.$ grain $\left.^{-1}\right)$ 影响却远没有增施氮肥的效 应明显, 因此灌浆结实期高温所引起的稻米蛋白相 对含量 $(\%)$ 上升现象，在很大程度上与高温胁迫处 理下的淀粉积累量下降和䛎藏蛋白占籽粒干重的相 对比例增加所引起的“浓缩效应”有关。此外，高温处 理与增施氮肥对稻米醇溶蛋白组分的影响存在明显 差别, 高温处理会引起稻米醇溶蛋白在相对含量 $(\%)$ 和绝对含量 $\left(\mathrm{mg} \mathrm{grain}^{-1}\right)$ 上均呈现明显下降, 并显著 提高稻米中的谷蛋白/醇溶蛋白比值, 而增施氮肥在 引起稻米谷蛋白含量提高的同时，稻米醇溶蛋白含 量也呈现上升趋势, 氮肥处理对谷蛋白/醇溶蛋白比 值的影响相对小于温度处理，说明灌浆结实期高温 造成的稻米食味品质下降现象, 并不是其在高温胁 迫下籽粒醇溶蛋白含量升高所引起的。高氮 + 高温处 理组合对稻米总蛋白与谷蛋白含量的影响程度要显 著大于单一高温或高氮处理，两因素对稻米总蛋白 含量和谷蛋白组分的影响存在一定程度的“累加”效 应，但增施氮肥可缓解稻米醇溶蛋白在高温胁迫下 的降低幅度, 有利于水稻在遭遇高温胁迫气候下稻 米醇溶蛋白含量的相对稳定。

\section{References}

[1] Fitzgerald M A, McCouch S R, Hall R D. Not just a grain of rice: the quest for quality. Trend Plant Sci, 2009, 14: 133-139.

[2] 黄发松, 孙宗修, 胡培松, 唐绍清. 食用稻米品质形成研究的 现状与展望. 中国水稻科学, 1998, 12: 172-176.

Huang F S, Sun Z X, Hu P S, Tang S Q. Present situations and prospects for the research on rice grain quality forming. Chin $J$ Rice Sci, 1998, 12: 172-176 (in Chinese with English abstract).

[3] Liu J C, Zhao Q, Zhou L J, Cao Z Z, Shi C H, Cheng F M. Influence of environmental temperature during grain filling period on granule size distribution of rice starch and its relation to gelatinization properties. J Cereal Sci, 2017, 76: 42-55.

[4] Dong W, Chen J, Wang L, Tian Y, Zhang B, Lai Y, Meng Y, Qian $\mathrm{C}$, Guo J. Impacts of nighttime post-anthesis warming on rice productivity and grain quality in East China. Crop J, 2014, 2: 63-69.

[5] Champagne E, Bett-Garber K, Thomson J, Fitzgerald M. Unraveling the impact of nitrogen nutrition on cooked rice flavor and texture. Cereal Chem, 2009, 86: 274-280.

[6] 胡群, 夏敏, 张洪程, 曹利强, 郭保卫, 魏海燕, 陈厚存, 韩宝 富. 氮肥运筹对钵苗机插优质食味水稻产量及品质的影响. 作物学报, 2017, 43: 420-431.

Hu Q, Xia M, Zhang H C, Cao L Q, Guo B W, Wei H Y, Chen H C, Han B F. Effect of nitrogen application regime on yield and quality of mechanical pot-seedlings transplanting rice with good taste quality. Acta Agron Sin, 2017, 43: 420-431 (in Chinese with
English abstract).

[7] 金正勋, 秋太权, 孙艳丽, 赵久明, 金学泳. 氮肥对稻米严白 及蒸煮食味品质特性的影响. 植物营养与肥料学报, 2001, 7: $31-35$.

Jin Z X, Qiu T Q, Sun Y L, Zhao J M, Jin X Y. Effect of nitrogen fertilizer on chalkiness ratio and cooking and eating quality properties of rice grain. Plant Nutr Fert Sci, 2001, 7: 31-35 (in Chinese with English abstract).

[8] 陶进, 钱希旸, 剧成欣, 刘立军, 张耗, 顾骏飞, 王志琴, 杨建 昌. 不同年代中籼水稻品种的米质及其对氮肥的响应. 作物 学报, 2016, 42: 1352-1362.

Tao J, Qian X Y, Ju C X, Liu L J, Zhang H, Gu J F, Wang Z Q, Yang J C. Grain quality and its response to nitrogen fertilizer in mid-season indica rice varieties planted in different decades from 1950s to 2010s. Acta Agron Sin, 2016, 42: 1352-1362 (in Chinese with English abstract).

[9] 徐正进, 陈温福, 马殿荣, 吴晓冬, 郑煜炎, 王嘉宇. 辽宁水 稻食味值及其与品质性状的关系。作物学报，2005，31: 1092-1094.

Xu Z J, Chen W F, Ma D R, Wu X D, Zheng Y Y, Wang J Y. Relationship between eating quality and other quality characters of rice in Liaoning. Acta Agron Sin, 2005, 31: 1092-1094(in Chinese with English abstract).

[10] 胡雅杰, 朱大伟, 邢志鹏, 龚金龙, 张洪程, 戴其根, 霍中洋, 许轫, 魏海燕, 郭保卫. 改进施氮运筹对水稻产量和氮素吸收 利用的影响. 植物营养与肥料学报, 2015, 21: 12-22.

Hu Y J, Zhu D W, Xing Z P, Gong J L, Zhang H C, Dai Q G, Huo Z Y, Xu K, Wei H Y, Guo B W. Modifying nitrogen fertilization ratio in increase the yield and nitrogen uptake of super japonica rice. Plant Nutr Fert Sci, 2015, 21: 12-22 (in Chinese with English).

[11] 张洪程, 吴桂成, 戴其根, 霍中洋, 许轫, 高辉, 魏海燕, 吕修 涛, 万鉦军, 黄银忠. 水稻氮肥精确后移及其机制. 作物学报, 2011, 37: 1837-1851.

Zhang H C, Wu G C, Dai Q G, Huo Z Y, Xu K, Gao H, Wei H Y, Lyu X T, Wan L J, Huang Y Z. Precise postponing nitrogen application and its mechanism in rice. Acta Agron Sin, 2011, 37: 1837-1851 (in Chinese with English abstract).

[12] 姚姝, 于新, 周丽慧, 陈涛, 赵庆勇, 朱镇, 张亚东, 赵春芳, 赵凌, 王才林. 氮肥用量和播期对优良食味粳稻直链淀粉含 量的影响. 中国水稻科学, 2016, 30: 532-540.

Yao S, Yu X, Zhou L H, Chen T, Zhao Q Y, Zhu Z, Zhang Y D, Zhao C F, Zhao L, Wang C L. Amylose content in good eating quality rice under different nitrogen rates and sowing dates. Chin $J$ Rice Sci, 2016, 30: 532-540 (in Chinese with English abstract).

[13] 刘巧泉, 周丽慧, 王红梅, 顾铭洪. 水稻种子晊藏蛋白合成的 分子生物学研究进展. 分子植物育种, 2008, 6: 1-15.

Liu Q Q, Zhou L H, Wang H M, Gu M H. Advances on biosynthesis of rice seed storage proteins in molecular biology. $\mathrm{Mol}$ Plant Breed, 2008, 6: 1-15 (in Chinese with English abstract).

[14] 陈能, 罗玉坤, 谢黎虹, 朱智伟, 段涁伍, 章林平. 我国水稻 品种的蛋白质含量及与米质的相关性研究. 作物学报, 2006, 32: 1193-1196.

Chen N, Luo Y K, Xie L F, Zhu Z W, Duan B W, Zhang L P. Protein content and its correlation with other quality parameters of rice in China. Acta Agron Sin, 2006, 32: 1193-1196 (in Chinese 
with English abstract).

[15] Krishman P, Ramakrishnan B, Reddy K R, Reddy V R. High temperature effects on rice growth, yield and grain quality. $A d v$ Agron, 2011, 111: 87-195.

[16] Hamaker B R, Griffin V K. Changing in the viscoelastic properties of cooked rice through protein disruption. Cereal Chem, 1990, 67: 261-264.

[17] Chrastil J. Correlations between the physicochemical and functional properties of rice. J Agric Food Chem, 1992, 40: 1683-1686.

[18] Lin C J, Li C Y, Lin S K, Yang F H, Huang J J, Liu Y H, Lur H S. Influence of high temperature during grain filling on the accumulation of storage proteins and grain quality in rice (Oryza sativa L.). J Agric Food Chem, 2010, 58: 10545-10552.

[19] Luthe D S. Storage protein accumulation in developing rice (Oryza sativa L.) seeds. Plant Sci Lett, 1983, 32: 147-158.

[20] Liu Z H, Cheng F M, Cheng W D, Zhang G P. Positional variations in phytic acid and protein content within a panicle of japonica rice. $J$ Cereal Sci, 2005, 41: 279-303.

[21] Yamagata H, Tanaka K. The site of synthesis and accumulation of rice storage proteins. Plant Cell Physiol, 1986, 27: 135-145.

[22] Zakaria S, Matsuda T, Tajima S, Nitta Y. Effect of high temperature at ripening stage on the reserve accumulation in seed in some rice cultivars. Plant Prod Sci, 2002, 5: 160-168.

[23] Dou Z, Tang S, Chen W Z, Zhang H X, Li G H, Liu Z H, Ding C Q, Chen L, Wang S H, Zhang H C, Ding Y F. Effects of open-field warming during grain-filling stage on grain quality of two japonica rice cultivars in lower reaches of Yangtze River delta. J Cereal Sci, 2018, 81: 118-126.

[24] 梁成刚, 陈利平, 汪燕, 刘佳, 许光利, 李天. 高温对水稻灌 浆期籽粒氮代谢关键酶活性及蛋白质含量的影响. 中国水稻 科学, 2010, 24: 398-402.

Liang C G, Chen L P, Wang Y, Liu J, Xu G L, Li T. Effects of high temperature on key enzyme activities of nitrogen metabolism and protein. Chin J Rice Sci, 2010, 24: 398-402 (in Chinese with English abstract).

[25] 马启林, 李阳生, 田小海, 鄢圣之, 雷慰慈, 中田升. 高温胁 迫对水稻䛎藏蛋白质的组成和积累形态的影响. 中国农业科 学, 2009, 42: 714-718.

Ma Q L, Li Y S, Tian X H, Yan S Z, Lei W C, Nakata N. Influence of high temperature stress on composition and accumulation configuration of storage protein in rice. Sci Agric Sin, 2009, 42: 714-718 (in Chinese with English abstract).

[26] 周广洽, 徐孟亮, 谭周, 李训贞. 温光对稻米蛋白质及氨基酸 含量的影响. 生态学报, 1997, 17: 537-542.

Zhou G Q, Xu M L, Tan Z, Li X Z. Effects of ecological factors of protein and amino acids of rice. Acta Ecol Sin, 1997, 17: 537-542 (in Chinese with English abstract).

[27] Altenbach S B. New insights into the effects of high temperature, drought and post-anthesis fertilizer on wheat grain development. J Cereal Sci, 2012, 56: 39-50.

[28] 韦克苏, 程方民, 董海涛, 张其芳, 刘奎刚, 曹珍珍. 水稻胚 乳咜藏物代谢相关基因对花后高温胁迫响应的微阵列检测, 中国农业科学, 2010, 43: 1-11.

Wei K S, Cheng F M, Dong H T, Zhang Q F, Liu K G, Cao Z Z.
Microarray analysis of gene expression profile related to grain storage metabolism in rice endosperms as affected by high temperature at filling stage. Sci Agric Sin, 2010, 43: 1-11 (in Chinese with English abstract).

[29] Yamakawa H, Hirose T, Kuroda M, Yamaguchi T. Comprehensive expression profiling of rice grain filling-related genes under high temperature using DNA microarray. Plant Physiol, 2007, 144: 258-277.

[30] Ashida K, Araki E, Maruyama-Funatsuki W. Temperature during grain ripening affects the ratio of type-II/type-I protein body and starch pasting properties of rice (Oryza sativa L.). J Cereal Sci, 2013, 57: 153-159.

[31] Xia N, Wang J M, Gong Q, Yang X Q, Yin S W, Qi J R. Characterization and in vitro digestibility of rice protein prepared by enzyme-assisted microfluidization: comparison to alkaline extraction. J Cereal Sci, 2012, 56: 482-489.

[32] Peng S B, Huang J L, Sheehy J E, Laza R C, Visperas R M, Zhong X H, Centeno G S, Khush G S, Cassman K G. Rice yields decline with higher night temperature from global warming. Proc Natl Acad Sci USA, 2004, 101: 9971-9975.

[33] Dou Z, Tang S, Li G, Liu Z H, Ding C Q, Chen L, Wang S H, Ding Y F. Application of nitrogen fertilizer at heading stage improves rice quality under elevated temperature during grain-filling stage. Crop Sci, 2017, 57: 2183-2192.

[34] 戴云云, 丁艳锋, 王强盛, 李刚华, 刘正辉, 王绍华. 不同施 氮水平下稻米品质对日间增温响应的差异. 植物营养与肥料 学报, 2009, 15: 276-282.

Dai Y Y, Ding Y F, Wang Q S, Li G H, Liu Z H, Wang S H. Effect of high day-time temperature on rice quality under different panicle nitrogen treatments. Plant Nutr Fert Sci, 2009, 15: 276-282(in Chinese with English abstract).

[35] Tang S, Zhang H, Liu W, Dou Z, Zhou Q Y, Chen W Z, Wang S H, Ding Y F. Nitrogen fertilizer at heading stage effectively compensates for the deterioration of rice quality by affecting the starch-related properties under elevated temperatures. Food Chem, 2019, 277: 455-462.

[36] 段骅, 傅亮, 剧成欣, 刘立军, 杨建昌. 氮素穗肥对高温胁迫 下水稻结实和稻米品质的影响. 中国水稻科学, 2013, 27: 591-602.

Duan H, Fu L, Ju C X, Liu L J, Yang J C. Effects of application of nitrogen as panicle-promoting fertilizer on seed setting and grain quality of rice under high temperature stress. Chin J Rice Sci, 2013, 27: 591-602 (in Chinese with English abstract).

[37] 吴翠平, 贺明荣, 张宾, 张洪华, 刘永环. 氮肥基追比与灌浆 中期高温胁迫对小麦产量和品质的影响. 西北植物学报, 2007, 27: 734-739.

Wu C P, He M R, Zhang B, Zhang H H, Liu Y H. Effects of nitrogen dressing ratios and heat stress during the middle period of grain filling on wheat grain yield and quality. Acta Bot BorealiOccident Sin, 2007, 27: 734-739 (in Chinese with English abstract).

[38] Ito S, Hara T, Kawanami Y, Watanabe T, Thiraporn K, Ohtake N, Sueyoshi K, Mitsui T, Fukuyama T, Takahashi Y, Sato T, Sato A, Ohyama T. Carbon and nitrogen transport during grin filling in rice under high-temperature conditions. J Agron Crop Sci, 2009, 195: 368-376. 